\title{
FRANK HOLLOWAY
}

\section{The community psychiatrist in 2008: anachronism, Cinderella or pioneer?}

Contemporary psychiatry in the UK is practised in an era where the deinstitutionalisation programme is virtually complete. The vast majority of the large mental hospitals (once called asylums) that dominated mental healthcare have closed to be replaced by a complex network of community services (including a 'virtual asylum' of residential and nursing home provision). Psychiatrists of past generations recall the excitement (and concern) associated with the concepts of 'community psychiatry' and 'community care': some, including me, were appointed to post as a consultant community psychiatrist. In the era of ubiquitous community care is the community psychiatrist an anachronism? Or does the recent call for in-patient psychiatry to be recognised as a specialism (Dratcu, 2006) imply its obvious corollary, the specialist community psychiatrist?

\section{What is community psychiatry?}

Like many concepts used in mental healthcare, community psychiatry has had many meanings over the years, as have its close cousins and occasional synonyms community care and community mental health. The Textbook of Community Psychiatry (Thornicroft \& Szmulker, 2001) lists eight previous definitions of the concept and provides a ninth, defining community psychiatry as 'the principles and practices needed to provide mental health services for a local population by: (i) establishing population-based needs for treatment and care; (ii) providing a service system linking a wide range of resources of adequate capacity operating in accessible locations; [and] (iii) delivering evidence-based treatments to people with mental disorders' (p. 3, italics in the original). Thus, by implication, the community psychiatrist will have a good grasp of epidemiology and be working within a (particular) locality, providing and supporting a range of services and clinical interventions tailored to meet local demand.

Broad though it is, this definition misses out other important elements of the concept which lie in what Rosen (2006) describes as the 'macrosphere of improving the mental health and well-being of whole communities'. These include the promotion of mental health awareness, social capital and emotional resilience within the general population; adopting strategies aimed at empowering people with mental health problems, and addressing stigma and discrimination; planning and reform of the mental healthcare system; and embracing sociological and anthropological perspectives that include working with local communities (as opposed to service systems) and making use of cultural tools and healing practices. Working within the mental health 'macrosphere' demands an even broader range of skills from the community psychiatrist.

\section{History}

How long has community care for people with mental illness been government policy in the UK? When asked this question people tend to identify the 1950s (when in 1954 the UK mental hospital population reached its peak, the open door movement revolutionalised the life of the traditional asylum and the groundbreaking Mental Health Act 1959 was passed), the 1960s (when in 1962 Enoch Powell, then Health Minister, made his famous 'Watertower' speech marking a plan to close the traditional mental hospitals and the movement for district general hospital psychiatry gained impetus), the 1970s (when the White Paper Better Services for the Mentally III was published (Department of Health, 1975)), or even the 1980s (when the large mental hospitals finally began to close and an important community care White Paper, Caring for People, was published (Department of Health, 1989)).

In fact the policy can be dated back to the publication of the Report of the Royal Commission on Lunacy and Mental Disorder in 1926 (Royal Commission, 1926), which led to the Mental Treatment Act 1930. This report is now remembered, if at all, for introducing voluntary admission to mental hospitals. However, it also identified mental illness as primarily a public health problem, set mental healthcare in the mainstream of medicine and encouraged the opening of out-patient clinics and the development of aftercare services. A mental healthcare system predicated on detention was to be replaced by one based on prevention and treatment. This formulation 
可

editorial is remarkably similar to that of Szmukler \& Thornicroft published 75 years later. It eventually led to the establishment in the 1990s of a model of adult mental healthcare in the UK which sought to provide comprehensive local services based on the community mental health team (CMHT) and its associated acute in-patient ward (Ramsay \& Holloway, 2007), with the consultant providing continuity between hospital and community.

The divergence between two conceptualisations of community psychiatry (in Rosen's terminology, the 'microsphere' and the 'macrosphere') was apparent early on. It relates to a distinction between the 'microsphere' of community-based treatment and care - underpinning developments in the UK - and a more overtly political attempt to work at the level of improving the mental health of the whole community - underpinning the US community mental health centre movement of the 1960 s and 1970s (Freeman, 1983). The latter is widely perceived to have been a failure (Mollica, 1983) and was memorably described as 'trying to drink the ocean' (Leighton, 1982).

\section{Where we are now}

Psychiatry has expanded and differentiated during the era of deinstitutionalisation. Specialties and sub-specialties have emerged. Psychotherapy, and child and adolescent psychiatry never had a significant institutional base. Old age psychiatry emerged partly as a product of the closure of large institutions and has always embraced a community orientation. Learning disability psychiatry was required to evolve rapidly in response to deinstitutionalisation - it is now profoundly community-oriented. Even forensic psychiatry, which remains primarily an institutionally-based specialty, now encompasses the community forensic team

Within general adult psychiatry there are now a number of clearly recognisable sub-specialties (rehabilitation, liaison, addictions, neuropsychiatry, eating disorders and perinatal psychiatry). These have varying degrees of institutional recognition and demonstrate varying engagement with the microsphere and macropsphere of community psychiatry. In addition, we have seen the emergence of a 'functionally differentiated' model of adult mental health services that includes a range of specialist community teams (providing crisis resolution/ home treatment, assertive outreach and early-onset psychosis services), specialist services providing National Institute for Health and Clinical Excellence (NICE)compliant psychological treatments and acute intensive care and low-secure in-patient services that have dedicated consultant input. This model potentially relegates the $\mathrm{CMHT}$ and its psychiatrist to a marginal role, with continuity between in-patient and community settings being provided by a care coordinator.

\section{The future}

Rosen (2006) set out some specific skills that a highquality community psychiatrist should possess over and above the good generalist: epidemiological understanding; psychotherapeutic skills that enable one to work in tricky extra-hospital situations; cultural competence; the wide range of skills required to work within the macrosphere that involves improving public mental health; and advanced management skills.

Few psychiatrists in the UK now identify themselves as community psychiatrists, a term that may have become an anachronism, merely of historical interest. The last obvious vestige of community psychiatry is the CMHT consultant, working within a closely-defined catchment area, now usually a set of general practices rather than a geographical area. The future of this role, in an era of well-resourced functional mental health teams and a drive to further specialisation based on advances in biomedicine, is far from clear. This is despite the continuing position of the CMHT as the core secondary mental health service. Community mental health team consultants may be forgiven for perceiving their role as Cinderellas of contemporary mental health services.

Psychiatry as a whole is inevitably and increasingly oriented towards the return of a patient, whatever their level of illness or disability, to life in the community, to supporting people out of hospital to live meaningful lives and to facilitating the individual's personal recovery (Care Services Improvement Partnership et al, 2007). This change in orientation away from traditional hospital care has obvious implications for training, which include the requirement for exposure to a wide range of care settings, the need to understand the social factors underlying mental illness and, crucially, the ability to work as a member of a multidisciplinary team and with other agencies (Linsley et al, 2001). We are in one sense perhaps all community psychiatrists now, and certainly no competent psychiatrist working in England can work in ignorance of the broader context of their work, including the implications of the Care Programme Approach (Kingdon \& Amanullah, 2005).

In a critique of the implementation of the policy of community care published over 30 years ago, Hawks (1975) characterised community care for people with mental illness as a moral enterprise that went beyond the then available evidence. Despite the spectacular success of deinstitutionalisation there remains much unfinished business. At the barest minimum we need to ensure that future training curricula include exposure to what is already known about psychiatric practice in the community (Linsley et al, 2001; Rosen, 2006). My personal hope is that a new generation of community psychiatrists will emerge who will act as pioneers in pursuing a conceptually complex and emotionally demanding agenda that requires them to engage ever more effectively with the community within which they work and where their patients live.

\section{Declaration of interest}

None. 


\section{References}

CARE SERVICES IMPROVEMENT PARTNERSHIP, ROYAL COLLEGE OF PSYCHIATRISTS \& SOCIAL CARE INSTITUTE FOR EXCELLENCE (2007) A Common Purpose: Recovery in Future Mental Health Services. Social Care Institute for Excellence (http:// www.spn.org.uk/fileadmin/ SPN_uploads/Documents/Papers/ SPN_Papers/recovery2.pdf).

DEPARTMENT OF HEALTH (1975) Bette Services for the Mentally III (Cmnd 6233). HMSO

DEPARTMENT OF HEALTH (1989) Caring for People: Community Care in the Next Decade and Beyond (Cm849). HMSO.
DRATCU, L. (2006) Acute in-patient psychiatry: the right time for a new speciality? Psychiatric Bulletin, 30, 401-402.

FREEMAN, H. (1983) Concepts of community psychiatry. British Journal of Hospital Medicine, 30,90-96.

HAWKS, D. (1975) Community care: an analysis of assumptions. British Journal of Psychiatry, 127, 276-285.

KINGDON, D. \&AMANULLAH, S. (2005) Care Programme Approach: relapsing or recovering? Advances in Psychiatric Treatment, 11, 325-329.

LEIGHTON, A. (1982) Caring for Mentally III People. Cambridge University Press.
LINSLEY, K., SLINN, R., NATHAN, R., et al (2001) Training implications of community-oriented psychiatry. Advances in Psychiatric Treatment, 7 208-215.

MOLLICA, R. F. (1983) From asylum to community. The threatened disintegration of public psychiatry. England Journal of Medicine, $\mathbf{3 0 8}$ 367-373.

RAMSAY, R. \& HOLLOWAY, F. (2007)

Mental health services. In General

Psychiatry. College Seminars in

Psychiatry (2nd edn) (eds G. Stein \&

G.Wilkinson), pp. 724-746. Gaskell.

A. (2006) The community psychiatrist of the future. Current Opinion in Psychiatry, 19,

$380-388$.

ROYAL COMMISSION (1926) Report of the Royal Commission on Lunacy and Mental Disorder (Cmd 2700).

SZMUKLER, G \& THORNICROFT, G. (2001) What is community psychiatry? In Textbook of Community Psychiatry (eds G. Thornicroft \& G. Szmukler), pp. 1-12. Oxford University Press.

Frank Holloway Consultant Psychiatrist and Clinical Director, Croydon Integrated Adult Mental Health Services, Bethlem Royal Hospital, Monks Orchard Road, Beckenham BR3 3BX, email: f.holloway@iop.kcl.ac.uk 